\title{
Influence of Geographical Location on the Occurrence of Domestic Violence among Women in Ekiti State, Nigeria
}

\author{
Eloh Modupe Mary, Akindutire Isaac Olusola
}

\begin{abstract}
This study investigated domestic violence and assessed the influence ofgeographical location on the occurrence of domestic violence among women in Ekiti State, whichmight assist policy makers in the health and education sectors to embark on awareness programs thatcan be helpful in reduction of cases of domestic violence in Ekiti State. The descriptive research design of the survey type was adopted for this study. The sample consisted of $\mathbf{2 1 0 0}$ women in Ekiti State. The sample was selected through Multistage sampling procedure. An adapted close-ended questionnaire was used to measure the variables investigated. Face and content validity of the instrument were ensured by the supervisor and other experts in Health Education and Tests and Measurement. Reliability of the instrument was ensured by having one shot test on respondents who were not part of the sample. The data collected was analysed using Crobach's alpha and a coefficientof 0.85 was obtained. The instrument was administered on the respondents in their place of residence by the researcher and twelve research assistants. The research question was answered with descriptive statistics of frequency counts, percentage, mean and bar chart. Hypothesis was tested at 0.05 level of significance using t-test. The findings of this study showed that $37.9 \%$ of the women experienced physical violence, $40.8 \%$ experienced sexual violence and $43 \%$ experienced psychological violence in Ekiti State. Geographical location significantly influenced the occurrence of domestic violence among women in Ekiti Statetcal(2.851) .

Based on findings of this study, it was recommended thatenlightenment programmeswhich might promote social and supportive environments that are intolerant towards domestic violence should be organized periodically especially in rural communities.
\end{abstract}

Index Terms - Awareness, Intimate partner,Location, Violence.

\section{INTRODUCTION}

Domestic violence, which can also be referred to as family violence is seen as a pattern of abusive behavior by one partner against another in an intimate relationship such as marriage, dating, family or cohabitation. It is a life-threatening problem that may primarily affect women and girls. Domestic violence may be exhibited in different forms, such as, physical assault, sexual assault, emotional abuse, rape, molestation, battering, corporal punishment, deprivation of rights and traditional practices that are harmful

Eloh Modupe Mary, lecturer at the College of Health Sciences and Technology IjeroEkiti, Ekiti State, Nigeria

Akindutire Isaac Olusola, Professor at the Faculty of Education, Ekiti State University, Ekiti State, Nigeria to women. It often has serious long-term consequences for the individuals involved, their families, communities, and society at large.

In Nigeria, there have been reports of cases of husbands battering, killing and maiming their wives in the media. In Ekiti State, it was reported that a 42 year-old man beat his wife to death for denying him sex in Erio-Ekiti [14]. Similarly, a wife, pleaded with IkoleEkiti customary court to dissolve her marriage to her husband due to neglect, lack of care and constant beating for not bearing male child [13]. Recently, a man residing in Ilasa-Ekiti, beheaded his betrothed wife for not coming to spend the Eld-el-Fitr holiday with him [15]. Reacting to the issue of domestic violence, the wife of the Ekiti state Governor, EreluBisiFayemi,lamented that this trend is increasing and becoming worrisome. She said Government was saddened that in spite of existing laws prohibiting gender violence, the state continues to witness issues of rape, defilement and human trafficking almost on daily basis [6].

As observed, rural and urban women are equally as likely to experience domestic violence. Women who experience domestic violence may face specific issues relating to their geographical location and the cultural and social characteristics of living in rural or urban communities. There seems to be a common view in rural communities in Ekiti State that "family problems" such as domestic violence are not talked about, which may serve to silence women's experience of domestic violence and deter them from disclosing abuse. Furthermore, fear of stigma, shame, community gossip, and a lack of perpetrator accountability may deter women from seeking help. Moreover, women who do seek help may find difficulty in accessing health and counseling services due to geographical isolation, lack of transportation options and not having access to their own income.Women in poverty living in rural or remote communities are more likely, to experience violence than others because urban women seem to be more educated and more economically empowered and understand their fundamental human rights better than their rural counterparts. The finding of a study [2] showed that, the burden of domestic violence in the Eastern part of Nigeria was high and that the rural women experienced higher levels of domestic violence compared to urban women.Likewise, another finding [8] showed that women in the rural setting are more likely to be victims of physical abuse $(90.41 \%)$ and verbal abuse $(91.78 \%)$ by their husbands than women in the urban setting. On the other hand, Benebo, Schumann and 
Vaezghasemi (2018)[4]found out that, women residing in rural areas had lower odds of experiencing intimate partner violence compared to their counterparts in urban areas. However, this association was not significant.

Based on the Ethiopian Central Statistical Agency (2012) [7], Domestic violence is common in Ethiopia both urban and rural families. About $68-81 \%$ of women agree to wife beating if husband has justified in at least one of specified situations. About $88 \%$ of rural and $69 \%$ of urban women in Ethiopia believe that their husbands have the right to beat them [1]. The study of Igbokwe et al. (2013) [8] revealed that women in the rural setting are more likely to be victims of physical abuse $(90.41 \%)$ and verbal abuse $(91.78 \%)$ by their husbands than women in the urban setting. Another study[16] on intimate partner violence in urban, rural, and remote areas showed that rurality was associated with the severity of intimate partner violence reported, as well as the presence of risk factors and their relationship to overall risk judgments but cases in remote areas included more severe IPV as well as more risk factors.

However, Oli (2012) [12] found out that, in terms of knowledge of agencies that deal with violence against women, the results showed that young, ever-married, respondents with medium level of education, urban residents and females were more knowledgeable of agencies that deal with violence against women. Most of the previous studies on domestic violence in Nigeria were based in urban hospitals or urban communities. Little is known about the prevalence of domestic violence in rural communities in Nigeria and there are few studies that have made a direct comparison between urban and rural women. This study was delimited to domestic violence against women by their male intimate partners (Intimate Partner Violence (IPV))and geographical location.

\section{A. Objectives Of The Study}

The objectives of this study are to:

i. Investigate domestic violence

ii. Compare the prevalence of domestic violence between women living in rural and urban areas of Ekiti State.

\section{METHODOLOGY}

The study was a descriptive research design of the survey type. The survey design was adopted because it made it possible to collect information from a large representative sample of the entire women population in Ekiti State and enabled the researcher to observe, describe and interpret the prevailing phenomena associated with domestic violence among women in Ekiti state. The population for this study comprised of all women in EkitiState with an estimate of 1,183,470 [10]. The sample for this study consisted of 2100 women aged 15 and above. The sample was selected through Multistage sampling procedure. The instrument for this study was a close-ended structured questionnaire. The instrument for measuring domestic violence was adapted from the compendium of Assessment Tools for Measuring Intimate Partner Violence Victimization and Perpetration, Center for Disease Control and Prevention, Atlanta, (2006) [5]. The instrument was subjected to face and content validity measures. The reliability of the instrument was ensured. A coefficient of 0.845 was obtained which indicated that the instrument had good internal consistency and was adequate for the study. Copies of the questionnaire were administered on 2100 respondents in their place of residence. Twelve research assistants, who were trained on the subject matter as well as modalities and the procedures to follow in the administration of the instrument, were employed to assist the researcher in the administration of the instrument. Both descriptive and inferential statistics were used to analyse the data.

\section{A. Limitation of the Study}

The researcher was unable to retrieve 45 copies of the questionnaire, some of which were not properly filled, and thus cancelled. Notwithstanding, this did not affect the result of this study as the instrument return rate was $97.9 \%$.

\section{RESULTS AND DISCUSSION}

\section{A. Results}

Question 1: Do women in Ekiti State experience domestic violence?

In answering the question, responses on the experience of domestic violence by women were obtained. Mean scores of responses for physical violence (9.34), sexual violence (8.98) and psychological violence (11.80) were used to categorize the respondents into experience and non-experience of domestic violence. Respondents who scored below the mean score were categorized into non-experience of domestic violence while those with scores equal to or above the mean score were categorized into experience of domestic violence. The responses were subjected to statistical analysis involving frequency counts and percentages. The result is presented in Table 1.

Table 1: Domestic Violence Experienced by Women in Ekiti State

\begin{tabular}{|l|l|l|l|l|c|}
\hline \multicolumn{1}{|c|}{$\begin{array}{c}\text { Types of } \\
\text { domestic } \\
\text { violence }\end{array}$} & \multicolumn{2}{|c|}{ Experience } & \multicolumn{2}{|c|}{ Non-Experience } & Ranking \\
\cline { 2 - 5 } & $\mathbf{N}$ & $\%$ & $\mathbf{N}$ & $\%$ & \\
\hline $\begin{array}{l}\text { Physical } \\
\text { violence }\end{array}$ & 778 & 37.9 & 1277 & 62.1 & $3^{\text {rd }}$ \\
\hline $\begin{array}{l}\text { Sexual } \\
\text { violence }\end{array}$ & 839 & 40.8 & 1216 & 59.2 & $2^{\text {nd }}$ \\
\hline $\begin{array}{l}\text { Psychological } \\
\text { violence }\end{array}$ & 883 & 43.0 & 1172 & 57.0 & $1^{\text {st }}$ \\
\hline
\end{tabular}

The result in Table 1 shows that 778 respondents representing $37.9 \%$ of the total sample experienced physical violence while $1277(62.1 \%)$ indicated non-experience. 839(40.8\%) respondents experienced sexual violence while $1216(59.2 \%)$ had no experience. On whether women experienced psychological violence, $883(43 \%)$ experienced it while $1172(57 \%)$ had no experience. This implies that women in Ekiti State experience domestic violence. The result is further presented in Figure 1. 


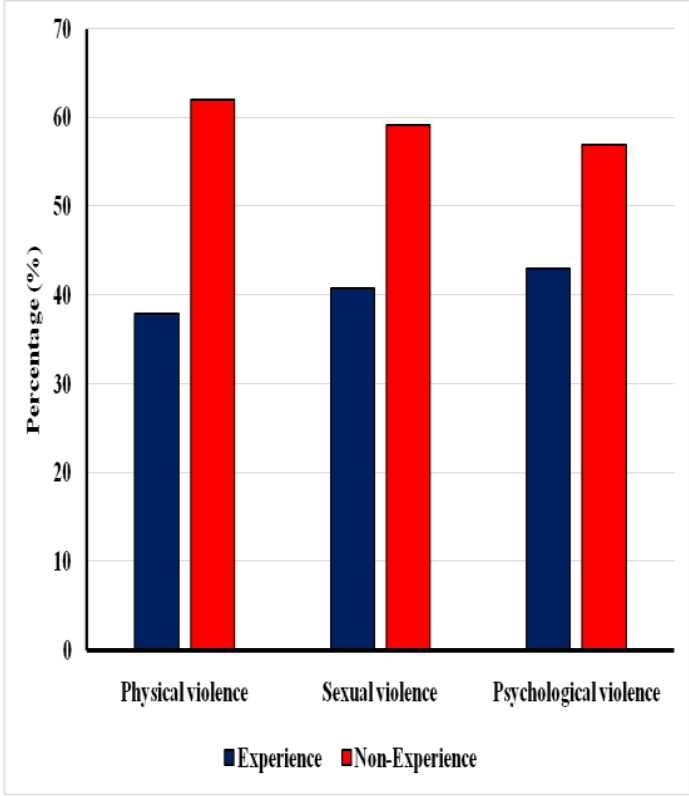

Fig. 1: Domestic Violence Experienced by women in Ekiti State

Hypothesis 1: There is no significant difference between urban and rural dwellers in the occurrence of domestic violence among women in Ekiti State.

Scores relating to occurrence of domestic violence among women were compared for statistical significance using t-test at 0.05 level of significance based on location. The result is shown in Table 2.

Table 2: Occurrence of Domestic Violence Among Women of by Location

\begin{tabular}{|l|c|c|c|r|r|r|}
\hline Group & $\mathbf{N}$ & Mean & SD & Df & $\mathbf{t}_{\text {cal }}$ & $\mathbf{t}_{\text {table }}$ \\
\cline { 1 - 4 } Urban & 1468 & 29.55 & 13.54 & \multirow{2}{*}{2053} & $2.851^{*}$ & 1.960 \\
\hline Rural & 587 & $\begin{array}{c}31 . \\
47\end{array}$ & 14.29 & & & \\
\hline
\end{tabular}

*p $<0.05$

Table 2 shows that $\mathrm{t}_{\text {cal }}(2.851)$ is greater than $\mathrm{t}_{\text {table }}(1.960)$ at 0.05 level of significance. The null hypothesis is rejected. This implies that there was significant difference between urban and rural dwellers in the occurrence of domestic violence among women in Ekiti State.

\section{DISCUSSION}

A finding from this study revealed that $37.9 \%$ women experienced physical violence, $40.8 \%$ experienced sexual violence and $43 \%$ experienced psychological violence in Ekiti State. This implies that women in Ekiti State experience domestic violence. This finding is consistent with the report of Nigeria Demographic and Health Survey (NDHS) (2013)
[11] which indicated that one in four ever-married women reported to have experienced physical, sexual, or emotional violence from their partner. This was also established by the study of Benebo et al., (2018)[4] which revealed that about one fourth of Nigerian women reported having ever experienced intimate partner violence. On the other hand, this finding showed a higher percentage of women who experienced domestic violence as against the finding of Akintoke (2008) [3], whose study revealed that $7 \%$ of women between the ages of 15 and 49 have undergone a form of sexual violence. The probable reason for this is not farfetched, as the society seems to be rapidly losing her core values, as exhibited in the nonchalant attitudes of some male domestic violence perpetrators, as evident on the social media that is consistently awash with news of such occurrences.The finding showed a significant difference between urban and rural dwellers in the occurrence of domestic violence among women in Ekiti State. This finding implies that domestic violence occurs among rural dwellers than urban dwellers in Ekiti State. This result agrees with Ajah et al., (2014) [2], who claimed that the rural women experienced higher levels of domestic violence compared to urban women. This reason for this could be that, the urban women were more educated and more economically empowered and understood their fundamental human rights better than their rural counterparts. This finding contradicts the finding of Benebo et al., (2018) [4] that women residing in rural areas had lower odds of experiencing intimate partner violence compared with their counterparts in urban areas. Although, McCarry and Williamson (2009) [9], made a submission that there are very few differences in the types and levels of violence and abuse that rural and urban women experienced.

\section{RECOMMENDATIONS}

Based on the findings of the studt, the following recommendations were made:

- Relationship education and other education programmes targeted at disrupting the developmental pathways toward domestic violence should be developed and implemented in health education curriculum, to achieving generational change in violent behaviour.

- Government and non-governmental organizations should make wider sensitization in rural areas by organizing workshops and seminars in the language of the community for effective communication.

\section{REFERENCES}

[1] Agumasie, S. \&Bezatu, M. (2015).Domestic violence against women and associated factors in Ethiopia; Systematic review.Reproductive Health, 12, 78-82.

[2] Ajah, L. O., Iyoke, C. A., Nkwo, P. O., Nwakoby, B. \&Ezeonu, P. (2014). Comparison of domestic violence against women in urban versus rural areas of southern Nigeria.International Journal of Women's Health, 6, 865-872.

[3] Akintoke, V. A. (2008). Domestic violence among couples in Ekiti State: An unpublished M.Ed Thesis, Ekiti State University, Ado-Ekiti.

[4] Benebo, F. O., Schumann,B. \&Vaezghasemi, M. (2018). Intimate partner violence against women in Nigeria: a multilevel study investigating the effect of women's status and community norms. 
BioMedCentral Women's Health18, 136-145. Retrieved April 10th 2019 from https://doi.org/10.1186/s12905-018-0628-7

[5] Center for Disease Control and Prevention, (2006). Measuring Intimate Partner Violence Victimization and Perpetration: A compendium of assessment tools Atlanta (GA).

[6] Daily Trust (2019, April, 5). Why rape, domestic violence on the increase in Ekiti. Retrieved on 5th July, 2019 from https://www.daily trust.com.ng

[7] Ethiopian Central Statistical Agency (2012). Ethiopia Demographic and Health Survey. Addis Ababa, Ethiopia and Calverton, Maryland, USA: Central Statistical Agency and ICF International.

[8] Igbokwe, C. C., Ukwuma M.C. \&Onugwu, K. J. (2013).Domestic violence against women: challenges to health and innovation.Journal of Research in National Development,11(2).Retrieved August 10th 2018 from www.transcampus.org/journals.

[9] McCarry, M. \& Williamson, E. (2009). Violence against women in rural and urban areas.University of Bristol.Retrieved May 2nd 2017 from www.briscol.ac.uk/sps/research/projects/current/rj5099

[10] National Population Commission (2006). Ekiti (State, Nigeria) Population statistics, charts, map and location. Retrieved August 26th from www.citypopulation.de/php/nigeria-admin.php?admlid=NGA013

[11] Nigeria Demographic and Health Survey (NDHS), (2013). Key findings- National Population Commission (Nigeria) and ICF International; Rockville, Maryland, USA. Retrieved August 10th 2018 fromhttps://www.dhsprogram.com

[12] Oli, N.P. (2012).Public perception on violence against women in urban and rural areas in Anambra State, Nigeria.Unpublished doctoral thesisUniversity Of Nigeria, Nsukka

[13] Omoluabi, (2017, 20 March). End time; husband beats wife for not bearing male child. Retrieved January 22nd 2018 from www.omoluabi.com.ng

[14] Punch newspaper (2016, August 11). Man beat wife to death for denying him sex. Retrieved April 22nd 2018 from http//punchng.com

[15] [15]Punch newspaper (2019, June 12). Herdsman allegedly beheads wife in Ekiti. Retrieved July 7th 2019 from http//punchng.com

[16] Strand, J.M. \&Storey, E.J. (2019). Intimate partner violence in urban, rural, and remote areas: An investigation of offense severity and risk factors. Violence Against Women 25(2), 188-207

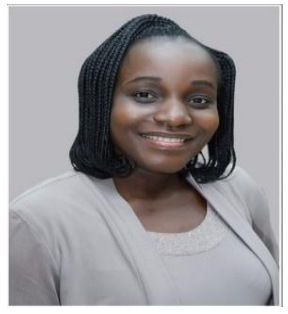

CoH, Modupe Mary is a lecturer at the College of Health Sciences and Technology IjeroEkiti, Ekiti State, Nigeria and a seasoned researcher. She holds a Doctor of Philosophy degree (Ph.D) in Health Education from Ekiti State University, Ekiti State, Nigeria. She is a registered and licensed Environmental Health Officer and a member of Academic Staff Union of Polytechnics. Her research interest is in health and educational issues.

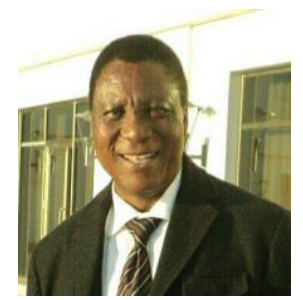

AKINDUTIRE, Isaac Olusola is a Professor at the Faculty of Education, Ekiti State University, Ekiti State, Nigeria. He is a member of Nigeria Association for Physical, Health Education and Recreation (NAPHER), Academic Staff Union of University and the New York Academy of Sciences. His research interest is in Administration of Sports, Physical fitness, Drugs in Sports and

health issues. 